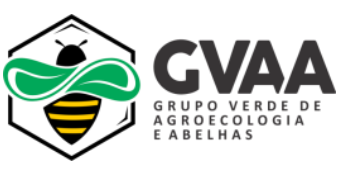

\title{
Resíduos de frutas na elaboração de geleia de melão Pele de Sapo
}

\section{Use of fruit residues in the production of Pele de Sapo melon jelly}

\author{
Lumara Tatiely Santos Amadeu ${ }^{1}{ }^{1}$; Rossana Maria Feitosa de Figueirêdo ${ }^{(2}{ }^{2}$; Alexandre José de Melo \\ Queiroz ${ }^{\left({ }^{3}\right.}$; Carolaine Gomes dos Reis ${ }^{\left(D^{4}\right.}$; Thalis Leandro Bezerra de Lima ${ }^{5}$; Patrícia da Silva Costa 6
}

\begin{abstract}
${ }^{1}$ Mestranda em Engenharia Agrícola, Universidade Federal de Campina Grande, Campina Grande, Paraíba, lumaratatiely1993@gmail.com; ${ }^{2}$ Professora no Centro de Tecnologia e Recursos Naturais, Universidade Federal de Campina Grande, Campina Grande, Paraíba, rossanamff@gmail.com; ${ }^{3}$ Professor no Centro de Tecnologia e Recursos Naturais, Universidade Federal de Campina Grande, Campina Grande, Paraíba, alexandrejmq@gmail.com; ${ }^{4}$ Mestranda em Engenharia Agrícola, Universidade Federal de Campina Grande, Campina Grande, Paraíba, carolainetecalimentos@gmail.com; ${ }^{5}$ Mestrando em Engenharia Agrícola, Universidade Federal de Campina Grande, Campina Grande, Paraíba, thallisma@gmail.com; ${ }^{6}$ Doutoranda em Engenharia Agrícola, Universidade Federal de Campina Grande, Campina Grande, Paraíba, patriciagroambiental@gmail.com.
\end{abstract}

\section{A R T I G O}

Recebido: $20 / 01 / 2020$

Aprovado: 04/03/2020

Palavras-chave:

Cucumis melo L.

Compostos bioativos

Resíduos agrícolas

\section{Key words:}

Cucumis melo L.

Bioactive compounds

Agricultural residues.

\begin{abstract}
R E S U M O
O aproveitamento de resíduos do processamento de frutas para desenvolvimento de novos produtos busca reduzir o desperdício, agregar valor a matéria prima e inserir no mercado um alimento com maior conteúdo nutricional, tendo em vista os compostos presentes em sementes e cascas. Diante disso, objetivou-se elaborar e caracterizar geleias de melão Pele de Sapo, cujas formulações foram: F1 [polpa: açúcar (1:1)]; F2 (F1 + 0,6\% sementes de maracujá) e F3 (F1 + 10\% cascas de melão). A polpa e as geleias foram caracterizadas quanto aos parâmetros físico-químicos e compostos bioativos. Verificou-se que as adições dos resíduos, com destaque para as cascas de melão, apresentaram-se como uma boa opção de aproveitamento, contribuindo com melhorias na qualidade do produto.

\section{A B S T R A C T}

The utilization of residues from fruit processing for the development of new products seeks to reduce waste, add value to the raw material and insert a food with greater nutritional content in the market, considering the compounds present in seeds and peels. Therefore, the objective was to elaborate and characterize Pele de Sapo melon jellies, whose formulations were: F1 [pulp: sugar (1: 1)]; F2 (F1 + 0.6\% passion fruit seeds) and F3 (F1 + 10\% melon peels). The pulp and jellies were characterized in terms of physical-chemical parameters and bioactive compounds. It was found that the addition of residues, especially melon peels, presented itself as a good use option, contributing to improvements in product quality.
\end{abstract}

\section{INTRODUÇÃO}

O melão (Cucumis melo L.) é uma das oleráceas mais populares do mundo, mostrando-se rico em minerais como cálcio, fósforo, sódio, magnésio e potássio, com um valor energético relativamente baixo, de 20 a $62 \mathrm{kcal} / 100 \mathrm{~g}$ de polpa e propriedades medicinais, sendo considerado calmante, alcalinizante, mineralizante, oxidante, diurético, laxante e emoliente (COSTA, 2017), além de ser fonte de compostos bioativos (compostos fenólicos e $\beta$-caroteno) que atuam como antioxidantes (LESTER, 2008).

É um fruto de grande importância para fruticultura, sendo produzido em diversas regiões, sobretudo no Nordeste (FREITAS et al., 2014), que segundo o IBGE (2018) é a região responsável por aproximadamente $95 \%$ da produção nacional, sendo o Rio Grande do Norte (338.615 t) e o Ceará (85.219 t) os maiores produtores, onde a maior parte das frutas produzidas é absorvida pela demanda interna, inclusive pela indústria processadora (ANUÁRIO, 2018).

Durante o processamento, aproximadamente $60 \%$ do melão, o que inclui cascas, sementes e sobras dos cortes, é descartado como resíduo (MIGUEL et al., 2008), gerando um desperdício que pode ser evitado tendo em vista as alternativas de aproveitamento existentes. Esses resíduos são ricos em vitaminas, minerais, lipídios e fibras que são compostos que possibilitam inúmeros benefícios à saúde e sua utilização no desenvolvimento de novos produtos, além de proporcionar a redução dos resíduos, contribui para o aumento do valor agregado do produto final (STORCK et al., 2013).

$\begin{array}{lc}\text { Revista Verde } & \text { v. } 15, \text { n.2, abr.-jun., p.153-159, } 2020 \\ \text { ISSN 1981-8203 } & \text { doi: } 10.18378 / \text { rvads.v15i2.7716 } \\ \text { Pombal, Paraíba, Brasil } & \end{array}$


As cascas de melão são constituídas principalmente por carboidratos, proteínas, fibras, minerais, polifenóis e pectina, o que possibilita sua utilização na elaboração de produtos alimentícios, como em geleias e doces, promovendo a redução dos resíduos a serem descartados no meio ambiente e enriquecendo nutricionalmente os produtos (MIGUEL et al., 2008; STORCK et al., 2013).

As sementes do maracujá amarelo (Passiflora edulis Sims) são consideradas fonte de ácidos graxos, com predominância do ácido linoleico, fibras insolúveis e proteínas, podendo ser utilizadas na indústria alimentícia (GROSSELI et al., 2014; FALEIRO; JUNQUIERA, 2016).

Tendo em vista os nutrientes presentes nos resíduos advindos da agroindútria, pesquisas têm sido realizadas na elaboração de geleias acrescidas de cascas e sementes de frutas, proporcionando características sensoriais inovadoras e contribuindo para o aumento da qualidade nutricional do produto. Mesquita et al. (2017) verificaram que sementes de mamão agregaram valor nutritivo às geleias de morango, com ótima aceitação sensorial, e que a utilização de sementes de mamão apresenta-se como uma boa alternativa para o aproveitamento de resíduos oriundos da industrialização do mesmo. Vieira et al. (2017) avaliaram a aceitabilidade e características físico-químicas de geleia mista de casca de abacaxi e polpa de pêssego verificando que o produto elaborado apresentou aceitação satisfatória para todos os atributos avaliados (aparência, sabor, aroma e cor).

Sendo assim, objetivou-se elaborar e caracterizar geleias de melão Pele de Sapo, adicionadas de cascas do mesmo melão e sementes de maracujá.

\section{MATERIAL E MÉTODOS}

O trabalho foi desenvolvido no Laboratório de Armazenamento e Processamento de Produtos Agrícolas (LAPPA) da Unidade Acadêmica de Engenharia Agrícola (UAEA), na Universidade Federal de Campina Grande.

\section{Processamento das matérias-primas}

Utilizou-se melões (Cucumis melo L.) da variedade Pele de Sapo oriundos do município de Mossoró, Rio Grande do Norte e maracujás cv. Amarelo (Passiflora edulis Sims) adquiridos no comércio local da cidade de Campina Grande PB. Ambos os tipos de frutos foram recepcionados e selecionados de acordo com estádio de maturação e ausência de danos físicos, sendo em seguida submetidos à lavagem com auxílio de esponja e posterior sanitização com solução de hipoclorito de sódio $(150 \mathrm{ppm})$ durante $15 \mathrm{~min}$ e enxágue em água corrente. Logo após, os melões foram descascados manualmente com facas de aço inoxidável, havendo a separação manual da polpa, cascas e sementes. Tanto a polpa quanto as cascas foram trituradas, separadamente, em liquidificador doméstico; em seguida apenas a polpa foi passada em peneira obtendo-se a polpa refinada.

Os maracujás foram cortados ao meio, separando-se a casca da polpa com sementes. A polpa com as sementes foi passada em peneira para separação de ambos. Como restou resíduo de polpa aderida às sementes, as mesmas foram cozidas em panela de aço inoxidável em fogo brando por cerca de $5 \mathrm{~min}$ para que o resíduo da polpa de maracujá se desprendesse (Figura 1A); em seguida essas sementes foram submetidas a sucessivas lavagens em água corrente para eliminação final da polpa residual e transferidas para peneira afim de eliminar a água superficial.

Figura 1. A: sementes de maracujá; B: cascas de melão cozidas; C: formulações - F1, F2 e F3, respectivamente
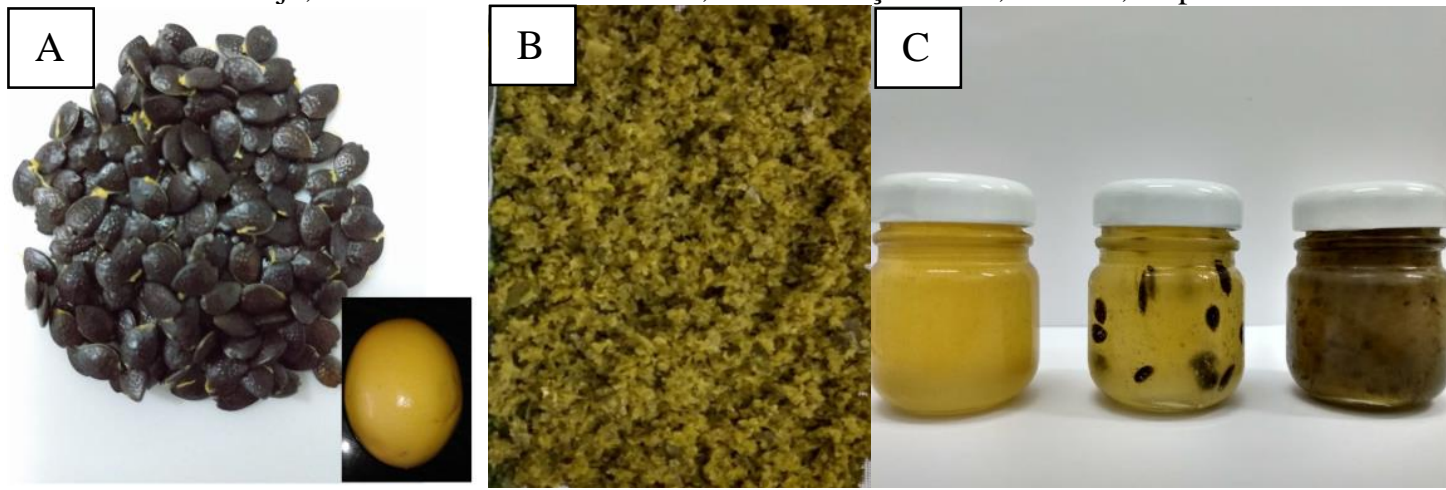

Fonte: Autores (2020)

\section{Elaboração das geleias}

Foram produzidas três formulações (Figura 1C) de geleias de melão Pele de Sapo do tipo extra, cuja proporção corresponde a 50 partes de polpa e 50 partes de açúcar. $\mathrm{Na}$ Tabela 1 têm-se as concentrações dos ingredientes para cada formulação.

Antes da elaboração das geleias, as cascas de melão foram pré-cozidas (Figura 1B) no vapor por $15 \mathrm{~min}$. Após esse processo, inicialmente misturou-se a polpa com água e metade do açúcar e de acordo com cada formulação incorporou-se as sementes de maracujá ou as cascas de melão, sendo realizada a correção do pH para faixa de 3,2 usando-se ácido cítrico, com o intuito de compensar a deficiência da polpa, que apresenta $\mathrm{pH}$ próximo da neutralidade. Posteriormente, as misturas foram transferidas para recipientes de aço inoxidável e submetidas a cocção, sob pressão atmosférica e com agitação manual. Imediatamente após a temperatura atingir valores entre 65-70 ${ }^{\circ} \mathrm{C}$ adicionou-se a pectina homogeneizada previamente com parte do açúcar, visando a não formação de grumos na geleia, sendo em seguida adicionado o restante do açúcar. A cocção foi 
mantida até que o produto atingisse entre 65 e $70{ }^{\circ}$ Brix conforme Krolow (2013). As geleias foram acondicionadas em potes de vidros com tampa metálica, previamente esterilizados com água a $100{ }^{\circ} \mathrm{C}$ durante 15 min para os recipientes e durante 5 min para as tampas. Após o envase das geleias, os recipientes foram fechados e invertidos por cerca de 5 min para maior aquecimento da tampa e vedação da mesma, logo retornados a posição de repouso. Por fim foram armazenadas sob refrigeração a $5{ }^{\circ} \mathrm{C}$ (UR 80-90\%) até a realização das análises.

Tabela 1. Formulação das geleias de melão Pele de Sapo do tipo extra

\begin{tabular}{lccc}
\hline \multirow{2}{*}{ Ingredientes } & \multicolumn{3}{c}{ Concentração (g) } \\
\cline { 2 - 4 } & $\mathrm{F} 1$ & $\mathrm{~F} 2$ & $\mathrm{~F} 3$ \\
\hline Polpa de melão refinada & 500,00 & 500,00 & 500,00 \\
Açúcar & 500,00 & 500,00 & 500,00 \\
Água & 200,00 & 200,00 & 200,00 \\
Pectina & 5,00 & 5,00 & 5,00 \\
Ácido cítrico & 6,76 & 6,72 & 6,97 \\
Sementes de maracujá & - & 6,00 & - \\
\hline
\end{tabular}

Cascas de melão

\section{Caracterização físico-química das geleias}

A polpa de melão e as geleias foram caracterizadas em triplicata conforme os procedimentos analíticos do Instituto Adolfo Lutz (IAL, 2008) quanto aos seguintes parâmetros: teor de umidade, pelo método gravimétrico em estufa a vácuo a 70 ${ }^{\circ} \mathrm{C}$ até massa constante; cinzas pela incineração das amostras em mufla a $550{ }^{\circ} \mathrm{C}$; sólidos solúveis totais em refratômetro portátil; pH em pHmetro; acidez total titulável por titulação da amostra com solução de $\mathrm{NaOH}$ a $0,1 \mathrm{M}$; açúcares totais, açúcares redutores e açúcares não redutores pelo método de Fehling. Os sólidos totais foram calculados por diferença do teor de umidade e a atividade de água foi determinada a $25{ }^{\circ} \mathrm{C}$ através da leitura direta em higrômetro Aqualab 3TE (Decagon Devices, Pullman, EUA). O teor de ácido ascórbico foi determinado segundo a metodologia da AOAC (2002), através da titulação com 2,6-diclorofenolindofenol sódio (DCFI), até obtenção de coloração rosa claro persistente, utilizando-se ácido oxálico como solução extratora (BENASSI; ANTUNES, 1998).

Em relação aos compostos bioativos, os compostos fenólicos totais foram determinados de acordo com a metodologia descrita por Waterhouse (2006) e as antocianinas e flavonoides foram determinadas utilizando-se a metodologia descrita por Francis (1982).

\section{Análise estatística}

O delineamento utilizado na análise estatística dos parâmetros físico-químicos e compostos bioativos das geleias foi o inteiramente casualizado com 3 tratamentos (F1, F2 e F3) e 3 repetições com os dados submetidos à análise de variância (ANOVA) e a comparação entre médias realizada usando o teste de Tukey a 5\% de probabilidade com auxílio do programa computacional Assistat versão 7.7 Beta (SILVA; AZEVEDO, 2016).

\section{RESULTADOS E DISCUSSÃO}

$\mathrm{Na}$ Tabela 2 estão apresentados os valores da caracterização físico-química da polpa de melão Pele de Sapo refinada. Observa-se o valor de 91,79\% para o teor de umidade, próximo ao encontrado na Tabela Brasileira de Composição de Alimentos (TACO, 2011), que é de 91,3\%. Valores superiores para o mesmo produto foram verificados por Silva et al. (2011) com média de $95,75 \%$ e por Silva et al. (2016) que obteve 94,28\% para polpa de melão Cantaloupe. O teor de umidade está relacionado diretamente com a conservação do produto durante seu armazenamento, valores elevados proporcionará a ocorrência de reações químicas, bioquímicas e o desenvolvimento de micro-organismos, que consequentemente poderá ocasionar a deterioração do produto (VIEIRA et al., 2012; BARROS et al., 2019), tornando-se um fator negativo. O teor de sólidos totais também se encontra próximo ao valor identificado na Taco (2011), que é de $8,7 \%$, demonstrando que apesar do refinamento da polpa, o percentual de sólidos totais não sofreu grandes alterações.

Tabela 2. Caracterização físico-química e compostos bioativos da polpa de melão Pele de Sapo refinada

Parâmetros

Teor de umidade (\%) Polpa de melão refinada

Sólidos totais (\%)

$91,79 \pm 0,10$

Atividade de água $\left(\mathrm{a}_{\mathrm{w}}\right) 25^{\circ} \mathrm{C}$

$8,21 \pm 0,10$

Cinzas (\%)

$0,993 \pm 0,001$

$\mathrm{pH}$

Acidez total titulável (\% ácido cítrico)

$0,33 \pm 0,01$

$6,13 \pm 0,01$

$0,18 \pm 0,00$

$8,00 \pm 0,00$

Sólidos solúveis totais ( ${ }^{\circ}$ Brix)

Ácido ascórbico (mg/100 g)

$0,26 \pm 0,00$

Açúcares redutores (\% glicose)

$3,49 \pm 0,02$

Açúcares não redutores (\% sacarose)

$0,31 \pm 0,01$

Açúcares totais (\% glicose)

$3,81 \pm 0,01$

Compostos fenólicos totais $(\mathrm{mg} / 100 \mathrm{~g})$

Flavonoides (mg/100 g)

$36,32 \pm 0,01$

$0,84 \pm 0,01$

Antocianinas (mg/100 g)

$0,09 \pm 0,01$

Para atividade de água, observa-se média de 0,993 e para o teor de cinzas $0,33 \%$, sendo este valor inferior ao encontrado por Silva et al. (2011) e Jesus et al. (2016) para polpa de melão Pele de Sapo $(0,72 \%)$ e polpa de melão concentrada $(0,81 \%)$, respectivamente, o que pode ser explicado devido ao refinamento no qual a polpa em questão foi submetida.

Para os parâmetros $\mathrm{pH}$, acidez total titulável e sólidos solúveis totais, obteve-se valores de $6,13,0,14 \%$ ácido cítrico e $8,0{ }^{\circ}$ Brix, respectivamente, sendo inferiores aos valores encontrados por Dalastra et al. (2016), em três variedades de melão, na qual o melão Pele de Sapo deteve valores médios de 6,49 para o $\mathrm{pH}, 0,24 \%$ de ácido cítrico para a acidez total titulável e $13,15^{\circ}$ Brix para os sólidos solúveis totais. Morgado et al. (2015) identificaram valor médio de $13,15{ }^{\circ}$ Brix para melões rendilhados 'Louis'. As diferenças nos valores dos parâmetros físico-químicos e compostos bioativos identificados em produtos agrícolas, estão associados ao clima e ao solo de onde provieram, incluindo-se o eventual uso de fertilizantes e de irrigação, estádio de maturação, variedade, entre outros fatores (KHAN et al., 2014).

O ácido ascórbico, com valor médio de $0,26 \mathrm{mg} / 100 \mathrm{~g}$, encontra-se abaixo do determinado por Jesus e seus colaboradores (2016) em polpa de melão concentrada $(1,26$ 
$\mathrm{mg} / 100 \mathrm{~g}$ ), sendo assim, pode ser considerado baixo para derivado de fruta, podendo estar associado ao tempo entre o despolpamento e a realização da análise, tendo em vista sua baixa estabilidade frente a diversos agentes, se degradando facilmente em meio alcalino, calor, luz e metais (Fe, $\mathrm{Cu}$ e $\mathrm{Zn}$ ), além de enzimas (CHIM et al., 2013; MOURA et al., 2019).

Verifica-se que o valor médio dos açúcares redutores foi de 3,49\% de glicose estando acima da média identificada por Russo et al. (2012) para melão Valenciano amarelo cv. inodorus, sendo esta de $1,81 \%$, o que pode implicar em maior doçura na polpa do melão Pele de Sapo refinada. Essa diferença pode estar relacionada as variedades de melões e com o grau de maturação dos frutos coletados. Os açúcares redutores apresentaram maior valor que os não redutores, comportamento esperado, pois de acordo com Bastos et al. (2016) polpas de frutas apresentam maior conteúdo de glicose e frutose, quando comparado ao conteúdo de sacarose.
Para os compostos fenólicos totais, o valor médio de 36,33 $\mathrm{mg} / 100 \mathrm{~g}$ supera o reportado por $\mathrm{Fu}$ et al. (2011) em estudo para determinar o conteúdo presente em 62 frutas, no qual encontraram para o melão Cantaloupe valor médio de $31,50 \mathrm{mg}$ EAG/100 g; e por Brito (2017) ao avaliar 6 variedades de melões, identificando para a polpa de melão Pele de Sapo valor médio de 17,2 mg EAG/100 g.

Na Tabela 3 tem-se os valores médios da caracterização físico-química e dos compostos bioativos das três formulações de geleias de melão Pele de Sapo. Os teores de umidade variaram de 23,60 a 29,71\% onde a amostra F1 apresentou o menor teor $23,60 \%$ ) e consequentemente o maior teor de sólidos totais $(76,40 \%)$ em relação às demais formulações. A adição de sementes de maracujá ou da casca de melão Pele de Sapo ocasionaram o aumento do teor de umidade, no entanto o valor médio do parâmetro em ambas as amostras mantiveram-se abaixo do valor máximo preconizado pela legislação brasileira (38\%) (BRASIL, 1978).

Tabela 3. Caracterização físico-química e compostos bioativos das geleias de melão Pele de Sapo.

\begin{tabular}{lccc}
\hline Parâmetros & $\mathrm{F} 1$ & $\mathrm{~F} 2$ & $\mathrm{~F} 3$ \\
\hline Teor de umidade $(\%)$ & $23,60 \pm 0,11 \mathrm{c}$ & $27,32 \pm 0,52 \mathrm{~b}$ & $29,71 \pm 0,35 \mathrm{a}$ \\
Sólidos totais $(\%)$ & $76,40 \pm 0,11 \mathrm{a}$ & $72,68 \pm 0,52 \mathrm{~b}$ & $70,29 \pm 0,35 \mathrm{c}$ \\
Atividade de água $\left(\mathrm{a}_{\mathrm{w}}\right) 25{ }^{\circ} \mathrm{C}$ & $0,790 \pm 0,001 \mathrm{c}$ & $0,825 \pm 0,002 \mathrm{a}$ & $0,822 \pm 0,001 \mathrm{~b}$ \\
Cinzas $(\%)$ & $0,28 \pm 0,01 \mathrm{~b}$ & $0,29 \pm 0,01 \mathrm{~b}$ & $0,36 \pm 0,00 \mathrm{a}$ \\
$\mathrm{pH}$ & $2,97 \pm 0,01 \mathrm{~b}$ & $2,99 \pm 0,02 \mathrm{~b}$ & $3,16 \pm 0,01 \mathrm{a}$ \\
Acidez total titulável (\% ácido cítrico) & $0,90 \pm 0,00 \mathrm{a}$ & $0,87 \pm 0,00 \mathrm{~b}$ & $0,87 \pm 0,00 \mathrm{~b}$ \\
Sólidos solúveis totais $\left({ }^{\circ}\right.$ Brix) & $67,83 \pm 0,29 \mathrm{a}$ & $65,00 \pm 0,00 \mathrm{c}$ & $65,83 \pm 0,00 \mathrm{~b}$ \\
Ácido ascórbico $(\mathrm{mg} / 100 \mathrm{~g})$ & $0,61 \pm 0,00 \mathrm{~b}$ & $0,46 \pm 0,01 \mathrm{c}$ & $0,84 \pm 0,01 \mathrm{a}$ \\
Açúcares redutores $(\%$ glicose) & $29,76 \pm 0,30 \mathrm{a}$ & $16,29 \pm 0,07 \mathrm{c}$ & $24,28 \pm 0,15 \mathrm{~b}$ \\
Açúcares não redutores $(\%$ sacarose) & $31,91 \pm 1,01 \mathrm{~b}$ & $43,95 \pm 0,46 \mathrm{a}$ & $32,92 \pm 0,46 \mathrm{~b}$ \\
Açúcares totais $(\%$ glicose) & $63,35 \pm 1,09 \mathrm{a}$ & $62,55 \pm 0,44 \mathrm{a}$ & $58,93 \pm 0,39 \mathrm{~b}$ \\
Compostos fenólicos $(\mathrm{mg} / 100 \mathrm{~g})$ & $66,49 \pm 0,47 \mathrm{~b}$ & $64,78 \pm 0,08 \mathrm{c}$ & $99,24 \pm 0,08 \mathrm{a}$ \\
Flavonoides (mg/100 g) & $0,92 \pm 0,01 \mathrm{c}$ & $1,12 \pm 0,01 \mathrm{~b}$ & $4,00 \pm 0,01 \mathrm{a}$ \\
Antocianinas $(\mathrm{mg} / 100 \mathrm{~g})$ & $0,05 \pm 0,01 \mathrm{c}$ & $0,09 \pm 0,01 \mathrm{~b}$ & $0,24 \pm 0,01 \mathrm{a}$ \\
\hline F1 - geleia de melão; F2 - geleia de melão $+0,6 \%$ sementes de maracujá; F3 - geleia de melão $+10 \%$ cascas de melão. \\
Médias seguidas por letras iguais na mesma linha, não diferem entre si a $5 \%$ de significância, pelo teste de Tukey.
\end{tabular}

Os valores de atividade de água diferiram estatisticamente para todas as geleias e variaram entre 0,790 e 0,825 , valor aproximado foi identificado por Silva et al. (2018) ao avaliarem geleia com resíduos de polpa de morango $(0,763)$, valor esse justificado pelos autores por ser um produto com alto teor de açúcares, visto que a água envolve os cristais de açúcar presente no material. De acordo com Oliveira et al. (2012) a atividade de água influência na estabilidade do produto, de modo que alimentos que apresentem valores entre 0,60 e 0,85 para este parâmetro estão suscetíveis a deterioração por bolores e leveduras. Dessa forma se torna necessária adição de conservantes para garantir a segurança do produto contra o desenvolvimento microbiano, aumentando consequentemente sua vida de prateleira (LEMOS et al., 2019).

Para o teor de cinzas, observa-se que as geleias F1 e F2 não diferiram estaticamente entre si, enquanto a F3 apresentou maior percentual. Miguel et al. (2008) afirmaram que as cascas de melão apresentam teor de cinzas de $0,98 \%$ e Jorge et al. (2009) relataram que as sementes de maracujá apresentam cerca de $1,47 \%$, assim verifica-se que apesar das sementes de maracujá apresentarem maior percentual de cinzas, sua concentração nas geleias é inferior (16 vezes menor) a das cascas de melão, o que justifica o maior percentual na formulação F3. Outros autores relataram teores de cinzas próximos aos encontrados no presente trabalho, como Garcia et al. (2017), trabalhando com geleia de buriti $(0,25 \%)$ e Oliveira et al. (2014b) com geleia de umbu-cajá $(0,40 \%)$.

Os valores quantificados para o $\mathrm{pH}$, variaram entre $2,97 \mathrm{e}$ 3,16, o que é um fator positivo, pois segundo Kadam e Balasubramanian (2011) pH inferiores a 4,5 resultam em um crescimento reduzido de micro-organismos, porém em valores abaixo de 3,0 ocorre tendência a sinérese (TELES et al., 2017). Resultados semelhantes foram encontrados por Paiva et al. (2015) ao estudarem geleia de melão e geleia mista de acerola e melão, com valores de 3,07 e 3,27, respectivamente.

Em relação aos sólidos solúveis totais, todas as amostras diferiram estatisticamente entre si e variaram de 65,00 a 67,83 ${ }^{\circ}$ Brix estando em conformidade com o intervalo (65-70 ${ }^{\circ}$ Brix) mencionado por Krolow (2013). A variação entre as geleias com relação a este parâmetro está relacionada ao tempo de cocção sob a qual cada formulação ficou exposta, além da quantidade desse parâmetro da matéria-prima utilizada. 
Para a acidez total tiulável, observa-se que a amostra F1 diferiu estatisticamente das demais, com valor médio de $0,90 \%$ de ácido cítrico. Valor semelhante foi identificado por Silva et al. (2019) para geleias de abacaxi com $15 \%$ de extrato de hibiscos, obtendo valor médio de $0,85 \%$ de ácido cítrico. As amostras produzidas apresentaram maior percentual de acidez em relação a polpa refinada, em função da adição de ácido cítrico durante sua produção. Krolow (2013) relatou que a adição de ácidos orgânicos é necessária em geleias para compensar qualquer deficiência do conteúdo natural das frutas, contribuindo para se obter boa geleificação, evitando a cristalização do açúcar durante o armazenamento e realçando o sabor das frutas.

Os teores de ácido ascórbico das formulações diferiram estatisticamente entre si, atingindo maior valor na amostra F3 com $0,89 \mathrm{mg} / 100 \mathrm{~g}$, o que pode estar associado ao tempo de cocção e a composição nutricional das cascas que de acordo com Storck et al. (2013) são fontes de vitaminas. Valor semelhante para esse parâmetro foi reportado por Souza et al. (2019) em geleias de bocaiuva com maracujá, também com $0,89 \mathrm{mg} / 100 \mathrm{~g}$. Entre a polpa de melão Pele de Sapo refinada $(0,26 \mathrm{mg} / 100 \mathrm{~g})$ e a geleia F1 $(0,61 \mathrm{mg} / 100 \mathrm{~g})$, ocorreu um aumento do ácido ascórbico, comportamento provavelmente relacionado ao aumento da concentração, resultante da cocção.

Verifica-se ainda que as geleias apresentaram maior percentual de açúcares não redutores quando comparado com os açúcares redutores, sendo o mesmo comportamento observado por Silva et al. (2013) ao avaliarem geleia de cajá, podendo ser justificado em razão da adição de grande quantidade de sacarose (açúcar cristal) às geleias, que é o principal açúcar não redutor. Outro fator que pode ser apontado para justificar a predominância dos açúcares não redutores em algumas geleias é a menor inversão da sacarose durante o processo de cocção (OLIVEIRA et al. 2014a). Valores inferiores aos encontrados nas formulações foram quantificados por Vieira et al. (2017) em geleia mista de casca de abacaxi e polpa de pêssego com teores de açúcares totais e redutores de 44,56 e 18,90 g/100 g, respectivamente. De acordo com Barros et al. (2019) a sacarose no processo de cocção auxilia na retenção de umidade e altera parâmetros como sabor, textura, cor e aroma; e os açúcares redutores presentes na geleia conferem brilho ao produto e podem proporcionar $o$ atraso da cristalização da sacarose que interfere consequentemente na diminuição do nível de doçura das mesmas (JACKIX, 1988).

Observa-se diferenças estatísticas entre as médias dos compostos fenólicos, flavonoides e antocianinas, apresentandose os maiores teores na amostra F3, com valores médios de $99,24,4,00$ e $0,24 \mathrm{mg} / 100 \mathrm{~g}$ respectivamente. Ao avaliarem geleia de maracujá com sementes de linhaça marrom, Moura et al. (2019) observaram valores de 1,04 a 1,94 mg/100 g para as antocianinas e de 5,30 a $7,17 \mathrm{mg} / 100 \mathrm{~g}$ para flavonoides; Lemos et al. (2019) reportaram valores médios de 2,92 a 6,79 mg/100 g para as antocianinas, em geleias de acerola e jabuticaba; Souza et al. (2018) identificaram para a geleia mista de umbu e mangaba teor dos compostos fenólicos com valor médio de 75 $\mathrm{mg} / 100 \mathrm{~g}$, estando dentro da faixa determinada para as geleias de melão Pele de Sapo (64,78 a 99,24 mg/100 g); valores próximos também foram relatados por Lima (2018) para geleias de uva e mista (carnaúba + uva) com valores médios dos compostos fenólicos de 73,12 e 107,20 mg AGE/100 g, respectivamente.

De acordo com Rufino et al. (2010) teores de compostos fenólicos totais inferiores a $100 \mathrm{mg} / 100 \mathrm{~g}$ classificam a polpa de melão e as geleias produzidas como baixo teor de compostos fenólicos. Apesar disso, observa-se que houve uma concentração desse parâmetro, flavonoides, antocianinas e ácido ascórbico nas geleias com relação a polpa de melão, apresentando-se como uma boa opção nutricional, visto que estes compostos possuem atividade antioxidante que atuam na redução de radicais livres associados à redução do risco de doenças cardiovasculares e neurodegenerativas (ABOULENEIN et al., 2013).

\section{CONCLUSÕES}

As formulações das geleias são opção de aproveitamento da polpa e casca de melão Pele de Sapo e das sementes de maracujá.

A adição das sementes de maracujá e casca de melão aumenta os teores de cinzas, compostos fenólicos, flavonoides e antocianinas nas geleias de melão e reduz a acidez.

\section{REFERÊNCIAS}

ABOUL-ENEIN, H.Y.; BERCZYNSKI, D. X.; KRUK, I. Phenolic compounds: the role of redox regulation in neurodegenerative disease and cancer. Mini Reviews in Medicinal Chemistry, v.13, n.3, p.385-398, 2013. $\underline{10.2174 / 1389557511313030007 .}$.

ANUARIO. Anuário Brasileiro da Fruticultura 2018. Santa Cruz do Sul: Editora Gazeta, 2018. 88p.

AOAC - Association of Official Analytical Chemists. Official methods of analysis of AOAC international. 16.ed. Maryland: AOAC, 2002. 1141p.

BARROS, S. L.; SILVA, W. P.; FIGUEIRÊDO, R. M. F.; ARAÚJO, T. J.; SANTOS, N. C.; GOMES, J. P. Efeito da adição de diferentes tipos de açúcar sobre a qualidade físicoquímica de geleias elaboradas com abacaxi e canela. Revista Principia, v.1, n.45, p.150-157, 2019.

BASTOS, J. S.; MARTÍnEZ, E. A.; SOUZA, S. M. A. Características físico-químicas da polpa de umbu (Spondias tuberosa Arruda Câmara) comercial: efeito da concentração. Journal of Bioenergy and Food Science, v.3, n.1, p. 11-16, 2016.

BENASSI, M. T.; ANTUNES, A. J. A. Comparison of metaphosphoric and oxalic acids as extractant solutions for the determination of vitamin $\mathrm{c}$ in selected vegetables. Arquivos de Biologia e Tecnologia, v.31, n.4, p. 507-513, 1998.

BRASIL. Ministério da Saúde. Agência Nacional de Vigilância Sanitária. Resolução CNNPA n ${ }^{\circ}$ 12, de 24 de julho de 1978. Aprova normas técnicas especiais relativas a alimentos (e bebidas), para efeito em todo território brasileiro. Diário Oficial da República Federativa do Brasil, Brasília, DF, 1978.

BRITO, E. dos S. Avaliação da capacidade antioxidante de variedades de melão (Cucumis melo L.) comercializadas no 
Brasil e determinação do teor de glutationa reduzida (GSH). 2017. 130f. Tese (Doutorado em Ciências de Alimentos) Universidade Estadual de Campinas, Campinas. 2017.

CHIM, J. F.; ZAMBIAZI, R. C.; RODRIGUES, R. DA S. Estabilidade da vitamina $\mathrm{c}$ em néctar de acerola sob diferentes condições de armazenamento. Revista Brasileira de Produtos Agroindustriais, v.15, n.4, p.321-327, 2013. 10.15871/15178595/rbpa.v15n4p321-327

COSTA, N. D. A cultura do melão. 2.ed. Brasília, DF: Embrapa Semiárido, 2017. 202p. (Coleção Plantar, 76).

DALASTRA, G. M.; ECHER, M. M.; KLOSOWSKI, E. S.; HACHMANN, T. L. Produção e qualidade de três tipos de melão, variando o número de frutos por planta. Revista Ceres, v.63, n.4, p.427-450, 2016. 10.1590/0034-737X201663040013.

FALEIRO, F. G.; JUNQUEIRA, N. T. V. Maracujá: o produtor pergunta, a Embrapa responde. 1.ed. Brasília, DF: Embrapa Cerrados, 2016. 341 p. (Coleção 500 perguntas, 500 respostas).

FRANCIS, F. J. Analysis of anthocyanins. In: MARKAKIS, P. (Ed). Anthocyanins as food colors. New York: Academic Press, p. 181-207, 1982.

FREITAS, L. D. A.; FIGUEIRÊDO, V. B.; PORTO FILHO, F. Q.; COSTA, J. C.; CUNHA, E. M. Crescimento e produção do meloeiro cultivado sob diferentes níveis de salinidade e nitrogênio. Revista Brasileira de Engenharia Agrícola e Ambiental, v.18, (Suplemento), p.20-26, 2014. 10.1590/18071929/agriambi.v18nsupps20-s26

FU, L.; XU, B.; XU, X.; GAN, R.; ZHANG, Y.; XIA, Q.; LI, H. Antioxidant capacities and total phenolic contents of 62 fruits. Food Chemistry, v.129, n.2, p.345-350, 2011. 10.1016/j.foodchem.2011.04.079.

GARCIA, L. G. C.; GUIMARÃES, W. F.; RODOVALHO, E. C.; PERES, N. R. A. A.; BECKER, F. S.; DAMIANI, C. Geleia de buriti (Mauritia flexuosa): agregação de valor aos frutos do cerrado brasileiro. Brazilian Journal of Food Technology, v. 20, e2016043, p.1-5, 2017. 10.1590/1981-6723.4316.

GROSSELI, M.; MORAES, M. B.; DAMACENO, B. F.; OKAWABATA, F. S.; TARDIVO, A. C. de B.; ALVES, M. J. Q. F. Uso da polpa e da casca do maracujá (Passiflora edulis $f$. flavicarpa) sobre o colesterol em coelhos com hipercolesterolemia experimental. Revista de Pesquisa e Inovação Farmacêutica, v.6, n.2, p.12-20, 2014.

IAL. Instituto Adolfo Lutz. Métodos físico-químicos para análise de alimentos. 1.ed. digital. São Paulo: IAL, 2008. 1020 p.

IBGE. Instituto Brasileiro de Geografia e Estatística. Produção agrícola municipal. IBGE, 2018. Disponível em: <https://www.sidra.ibge.gov.br> Acesso em 10 jan. 2020.

JACKIX, M. H. Doces, geleias e frutas em calda. Campinas: Ed. UNICAMP, 1988. 171 p.

JESUS, G. F.; BASTOS, J. S.; OLIVEIRA, N. A.; ANJOS, M. B.; SANTOS, J. C. R.; SOUZA, S. M. A.; MARTINEZ, E. A.
Estudos preliminares na formulação de estruturados de mix de polpa de frutas. Revista do Congresso Sul Brasileiro de Engenharia de Alimentos, v.2, n.1, p.1-10, 2016.

JORGE, N.; MALACRIDA, C. R.; ANGELO, P. M.; ANDREO, D. Composição centesimal e atividade antioxidante do extrato de sementes de maracujá (Passiflora edulis) em óleo de soja. Pesquisa Agropecuária Tropical, v. 39, n. 4, p. 380-385, 2009.

KADAM, D. M.; BALASUBRAMANIAN, S. Foam mat drying of tomato juice. Journal of Food Processing and Preservations, v.35, n.4, p.488-495, 2011. 10.1111/j.17454549.2010.00492.x.

KHAN, A. A.; SAJID, M.; RAB, A. Tomato fruit quality as affected by different sources of phosphorus. Pakistan Journal of Nutrition, v.13, n.12, p.692-699, 2014. 10.3923/pjn.2014.692.699.

KROLOW, A. C. R. Preparo artesanal de geleias e geleiadas. 2.ed. Pelotas: Embrapa Clima Temperado, 2013. 38 p. (Documentos, 138).

LEMOS, D. M.; ROCHA, A. P. T.; GOMES, J. P.; OLIVEIRA, E. N. A.; SOUSA, E. P.; SILVA, S. F. Elaboração e caracterização de geleia prebiótica mista de jabuticaba e acerola. Brazilian Journal of Food and Technology, v. 22, p. 113, 2019. 10.1590/1981-6723.09818.

LESTER, G. E. Antioxidant, sugar, mineral, and phytonutrient concentrations across edible fruit tissue of orange-fleshed honeydew melon (Cucumis melo L.). Journal of Agricultural and Food Chemistry, v.56, n.10, p.3694-3698, 2008. 10.1021/jf8001735.

LIMA, J. S. Avaliação do teor de compostos fenólicos totais, capacidade antioxidante e análise sensorial de geleia mista de uva Isabel com carnaúba. 2018. 47f. Monografia (Bacharel em Nutrição), Universidade Federal de Campina Grande, Cuité. 2018.

MESQUITA, M. S.; GONÇALVES, C. A. A.; CRUZ, V. A.; MASSON, G. A.; ALVAREZ, M. C.; COSTA, L. L. Avaliação centesimal e sensorial da geleia de morango com adição de semente de mamão (Carica papaya). In: SEMINÁRIO DE PESQUISA E INOVAÇÃO TECNOLÓGICA, 1., Uberaba. Anais... Uberaba: IFTM, 2017. p. 1-9

MIGUEL, A. C. A.; ALBERTINI, S.; BEGIATO, G. F.; DIAS, J. R. P. S.; SPOTO, M. H. F. Aproveitamento agroindustrial de resíduos sólidos provenientes do melão minimamente processado. Ciência e Tecnologia de Alimentos, v.28, n.3, p.733-737, 2008. 10.1590/S0101-20612008000300033.

MORGADO, C. M. A.; MATTIUZ, C. F. M.; MUNIZ, A. C.; CHARLES, F.; MATTIUZ, B. Qualidade de melões 'Louis' armazenados em quatro temperaturas. Ciência Rural, v.45, n.11, p.1953-1958, 2015. 10.1590/0103-8478cr20140948.

MOURA, H. V.; SILVA, E. T. V.; FIGUEIRÊDO, R. M. F.; MOREIRA, I. S.; QUEIROZ, A. J. M. Produção e caracterização de geleias de maracujá com sementes de linhaça 
marrom. Revista Brasileira de Higiene e Sanidade Animal, v.13, n.2, p.218-229, 2019. 10.5935/1981-2965.20190016.

OLIVEIRA, J. A. R.; CARVALHO, A. V.; MARTINS, L. H. S.; MOREIRA, D. K. T. Elaboração e caracterização físicoquímica e sensorial de estruturados de polpa concentrada de abacaxi. Alimentos e Nutrição, v.23, n.1, p.23-31, 2012.

OLIVEIRA, E. N. A.; ROCHA, A. P. T.; GOMES, J. P.; SANTOS, D. C. Influência das variáveis de processo nas características físicas e químicas de geleias de umbu-cajá. Bioscience Journal, v.30, n.6, p. 1698-1710, 2014a.

OLIVEIRA, E. N. A.; SANTOS, D. C.; ROCHA, A. P. T.; GOMES, J. P. Desenvolvimento, caracterização e estabilidade de geleia tradicional de umbu-cajá. Revista Brasileira de Fruticultura, v.36, n.3, p.640-651, 2014b. 10.1590/0100-2945366/13.

PAIVA, C. A; AROUCHA, E. M. M.; FERREIRA, R. M. A.; ARAÚJO, N. O.; SILVA, P. S. L. Alterações físico-químicas de geleias de melão e acerola durante o armazenamento. Revista Verde de Agroecologia e Desenvolvimento Sustentável, v. 10, n. 3, p. 18-23, 2015. 10.18378/rvads.v10i3.3495.

RUFINO, M. S. M.; ALVES, R. E.; BRITO, E. S.; PÉREZJIMÉNEZ, J.; SAURA-CALIXTO, F.; MANCINI-FILHO, J. Bioactive compounds and antioxidant capacities of 18 nontraditional tropical fruits from Brazil. Food Chemistry, v.121, n.4, p.996-1002, 2010. 10.1016/j.foodchem.2010.01.037.

RUSSO, V. C.; DAIUTO, E. R.; VIEITES, R. L. Fresh cut yellow melon (CAC) submitted to different type cuts and concentrations of calcion chloride stored under modified passive atmosphere. Semina: Ciências Agrárias, v.33, n.1, p. 227-236, 2012. 10.5433/1679-0359.2012v33n1p227.

SILVA, F. A. S.; AZEVEDO, C. A. V. The Assistat Software version 7.7 and its use in the analysis of experimental data. African Journal of Agricultural Research, v.11, n.39, p.37333740, 2016.

SILVA, L. M. M.; FIGUEIREDO, R. M. F.; SOUSA, F. C.; SOUSA, E. P.; LIMA, A. K. V. O. Parâmetros químicos, físicos e físico-químicos de três variedades de melão. Revista Verde de Agroecologia e Desenvolvimento Sustentável, v.6, n.5, p.242246, 2011.

SILVA, M. J. S.; MOREIRA, I. S.; SULINO, R. F.; AUGUSTO, F. R.; OLIVEIRA, M. N. Elaboração e avaliação da qualidade sensorial e físico-química de geleia de cajá. Revista Verde de Agroecologia e Desenvolvimento Sustentável, v.7, n.3, p.14-20, 2013.

SILVA, G. D.; BARROS, Z. M. P.; MEDEIROS, R. A. B.; CARVALHO, C. B. O.; BRANDAO, S. C. R.; AZOUBEL, P. M. Pretreatments for melon drying implementing ultrasound and vacuum. Food Science Technology, v.74, p.114-119, 2016. 10.1016/j.lwt.2016.07.039.

SILVA, N. F. I.; SANTOS, F. S.; LIMA, A. R. C.; PEREIRA, P. K. G.; SILVA, M. J. S. Aproveitamento do resíduo da polpa de morango na elaboração de geleia. In: CIRNE, L. E. M. R.;
FRANCISCO, P. R. M.; FARIAS, S. A. R.; FURTADO, D. A.; SOUZA, P. M.; MORAIS, M. R.; MELO, M. C.; FARIAS; C. A. S. Gestão integrada de resíduos: universidade \& comunidade. Campina Grande: UFCG/APGRAF, 2018, v. 3, p. $69-72$.

SILVA, E. T. V.; MOURA, H. V.; FIGUEIREDO, R. M. F.; QUEIROZ, A. J. M.; MOREIRA, I. S. Production and characterization of mixed pineapple and hibiscus jam. Revista agro@mbiente on-line, v.13, p.155, 2019. 10.18227/19828470ragro.v13i0.5523.

SOUZA, H. R. S.; CARVALHO, M. G.; SANTOS, A. M.; FERREIRA, I. M.; SILVA, A. M. O. Compostos bioativos e estabilidade de geleia mista de umbu (Spondias tuberosa Arr. C.) e mangaba (Hancornia speciosa G.). Revista Brasileira de Higiene e Sanidade Animal, v.12, n.2, p.236-248, 2018. 10.5935/1981-2965.20180023.

SOUZA, R. S.; CUELLAR, J. P.; DONADON， J. R.; GUIMARÃES, R. C. A. Compostos bioativos em geleia de bocaiuva com maracujá. Multitemas, v.24, p.1-16, 2019. 10.20435/multi.v0i_.1803.

STORCK, C. R.; NUNES, G. L.; OLIVEIRA, B. B.; BASSO, C. Folhas, talos, cascas e sementes de vegetais: composição nutricional, aproveitamento na alimentação e análise sensorial de preparações. Ciência Rural, v.43, n.3, p. 537-543, 2013. 10.1590/S0103-84782013000300027.

TACO. Tabela brasileira de composição de alimentos. 2.ed. Campinas: NEPA-UNICAMP, 2011. 40p.

TELES, A. C. M.; PINTO, E. G.; SANTOS, J. R.; OLIVEIRA, C. F. D.; SOARES, D. S. B. Desenvolvimento e caracterização físico-química de geleia comum e extra de graviola com pimenta. Revista de Agricultura Neotropical, v.4, n.1, p.72-77, 2017.

VIEIRA, E. S.; JESUS, J. L.; REIS, R. C.; FONSECA, M. D.; SACRAMENTO, C. K. Physicochemical and sensorial characterization of papaya and araça boi jelly. Revista Brasileira de Fruticultura, v.34, n.4, p.1154-1164, 2012. 10.1590/S0100-29452012000400024

VIEIRA, E. C. S.; SILVA, E. P.; AMORIM, C. C. M.; SOUSA, G. M.; BECKER, F. S.; DAMIANI, C. Aceitabilidade e características físico-químicas de geleia mista de casca de abacaxi e polpa de pêssego. Cientifica: Revista de Agronomia, v.45, n.2, p.115-122, 2017. 5529.2017v45n2p115-122.

WATERHOUSE, A. Folin-ciocalteau micro method for total phenol in wine. American Journal of Enology and Viticulture, p.3-5, 2006. 